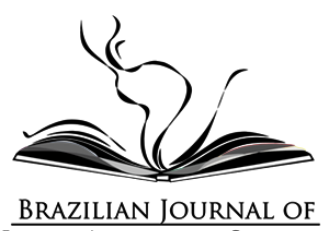

\title{
BRASIL E ARGENTINA: OS DISCURSOS SOBRE AS REGIÕES SEMIÁRIDAS DO CEARÁ E DE SANTIAGO DEL ESTERO NOS PERIÓDICOS CORREIO DA MANHÃ E EL MUNDO (1932-1937)
}

\author{
BRAZIL AND ARGENTINA: DISCOURSES OVER SEMIARID REGIONS OF \\ CEARÁ AND SANTIAGO DEL ESTERO ON THE NEWSPAPERS CORREIO DA \\ MANHÃ AND EL MUNDO (1932-1937)
}

BRASIL Y ARGENTINA: LOS DISCURSOS SOBRE LAS REGIONES DE CEARÁ $Y$ DE SANTIAGO DEL ESTERO EN LOS PERIÓDICOS CORREIO DA MANHÃ Y EL MUNDO (1932-1937)

\author{
Leda Agnes Simões de Melo' iD \\ Universidade do Estado do Rio de Janeiro, Brasil
}

Resumo: Na América Latina, países são acometidos pelo fenômeno das estiagens e são compostos por áreas semiáridas, como são os casos do Brasil e da Argentina. Respectivamente no Ceará (nordeste brasileiro) e em Santiago del Estero (noroeste argentino) a seca perpassa a história dessas regiões ao longo dos séculos. Para este trabalho, pretende-se analisar os discursos em torno das secas que ocorreram no Ceará e em Santiago del Estero na década de 1930, sob a ótica da imprensa das capitais nacionais. Especificamente analisaremos as narrativas do Correio da Manhã, do Rio de Janeiro, para o caso cearense, e do jornal El Mundo, de Buenos Aires, para o caso de Santiago del Estero. Interessa-nos, particularmente, compreender como ainda na década de 1930 na América Latina, tendo como enfoque uma história regional, os discursos sobre as áreas do interior vinculavam-se às ideias de progresso e de modernidade que estiveram no bojo da imagem de nação cunhada no século XIX, e que deixaram grande vestígio no século XX. Assim, propomos refletir como os discursos constroem percepções do social e são legitimadores, sobretudo, de domínio e poder político.

Palavras-chave: Semiárido, Discurso, Modernidade

Abstract: In Latin America, countries are affected by the natural phenomenon of droughts and are composed by semiarid areas, such as Brazil and Argentina's cases. Respectively in Ceará (northeast region of

'Doutora em História Social pelo Programa de Pós-Graduação em História Social da Faculdade de Formação de Professores da Universidade do Estado do Rio de Janeiro(FFP/UERJ). Bolsista CAPES. Este artigo é fruto das pesquisas da tese de doutorado. E-mail: ledagnes@hotmail.com 
Brazil) and Santiago del Estero (northwest region of Argentina), the drought events are part of their history throughout the centuries. For this paper, we intend to analyze the discourse around the drought events that occured in Ceará and Santiago del Estero in the decade of 1930, under their national capitals press' point of view. We will analyze, more specifically, the narratives contained in Correio da Manhã, located in Rio de Janeiro for Ceará's case, and in newspaper El Mundo, located in Buenos Aires, for the Santiago del Estero's. We are particularly yet interested in understanding how in the Latin America from the 1930 decade, focusing on a regional history, the discourses around the countryside areas were related to the ideas of progress and modernity which were on top of the image for a nation forged on the XIX century and lingered through the XX century. That way, we propose to reflect upon discourses that build social notions and are legitimizers, above all, of dominance and political power relations.

Keywords: Semiarid, Discourse, Modernity

Resumen: En América Latina, países son afectados por el fenómeno de la sequía y están compuestos por áreas semiáridas, como son los casos de Brasil y Argentina. En Ceará (noreste de Brasil) y Santiago del Estero (noroeste de Argentina), respectivamente, la sequía ha impregnado la historia de estas regiones a lo largo de los siglos. Para este trabajo, pretendemos analizar los discursos sobre las sequías ocurridas en Ceará y Santiago del Estero en la década de 1930, desde la perspectiva de la prensa de las capitales nacionales. Específicamente, analizaremos las narrativas de Correio da Manhã, del Río de Janeiro, para el caso de Ceará, y del periódico El Mundo, de Buenos Aires, para el caso de Santiago del Estero. Estamos, particularmente, interesados en comprender cómo, incluso en la década de 1930 en América Latina, centrándose en una historia regional, los discursos sobre las áreas del interior estaban vinculados a las ideas de progreso y modernidad que estaban en el centro de la imagen de nación acuñada en el siglo XIX, y que dejaron un gran rastro en el siglo XX. Por lo tanto, proponemos reflejar cómo los discursos construyen percepciones de lo social y legitiman, sobre todo, el dominio y el poder político.

Palabras-clave: Semiáridos, Discurso, Modernidad

DOI:10.11606/issn.1676-6288.prolam.2020.167978

Recebido em: 27/03/2019 Aprovado em: 28/07/2020

\section{INTRODUÇÃO}

No Brasil e na Argentina, existem áreas semiáridas acometidas pelo fenômeno da seca e que, apesar de não estarem próximas no mapa da América Latina, encarnam, além da geografia semiárida, uma 
desigualdade social que perpassa suas histórias. Na década de 1930, ambas foram acometidas por uma forte estiagem, que levou a uma onda de fome, sede, migrações e desemprego, foram elas: o estado do Ceará, localizado no Nordeste do Brasil, e a província de Santiago del Estero, localizada na região Noroeste da Argentina, Destaca-se como auge da crise climática o ano de 1932, no Ceará, e o ano de 1937, em Santiago del Estero.

Cabe situar que a região do Nordeste brasileiro é composta pelos estados do Maranhão, Piauí, Ceará, Rio Grande do Norte, Paraíba, Pernambuco, Alagoas, Bahia e Sergipe. Nessa área "o São Francisco separava o Nordeste do Leste e Sergipe e Bahia estavam integrados no Leste" (ANDRADE, 1988, p.6). De acordo com Manuel Correia de Andrade, o Nordeste tornou-se desde o século XVIII fornecedor de mão de obra para o Sudeste, e também um grande produtor de açúcar de cana, de álcool, fumo, cacau, carnaúba e algodão. Os sertões vão da margem direita do Rio Parnaíba até o Rio Itapicuru, abrangendo os estados do "Piauí, Ceará, Rio Grande do Norte, Paraíba, Pernambuco, Alagoas, Sergipe e Bahia" (AB'SÁBER, 1999, p.14). De acordo com Ab'Sáber, é um território duas ou três vezes maior que o estado de São Paulo. Refere-se regionalmente à extensão de Poções e Milagres, município de Amargosa na Bahia, até o noroeste do Ceará (AB'SÁBER, 1999), uma "região quente no interior, de altitude de 100 a 300m" (DUQUE, 2004, p.87). Andrade explica que é uma região extensa onde predominam pequenas quantidades de chuvas concentradas, apenas, em três ou quatro meses do ano, muito conhecida por sua originalidade e, principalmente, "pela propagação de notícias sensacionalistas de suas secas periódicas nos jornais brasileiros e estrangeiros" (ANDRADE, 1977, p.128). O clima, portanto, é tropical seco, com chuvas escassas, o que, de acordo com Josué de Castro (1984), empobrece o solo pela erosão e leva as crises de fome na região.

Já a região do Noroeste Argentino (NOA) tem seus limites com o Chile (oeste) e a Bolívia (norte). As províncias que a compõem são Jujuy, Salta, Tucumán, Catamarca e Santiago del Estero, que representam cerca de $16,7 \%$ do total da superfície continental do país (BOBBA, 2011, p.3). 
Existem nessa extensão territorial diferentes ambientes desde bosques, estepes arbustivos e graminosos, até o deserto. Destaca-se, também, o chamado Parque Chaqueño onde há uma área mais seca, denominada Chaco Semiárido, e nela se encontram as regiões de Formosa, Chaco, Salta, Tucumán, Santiago del Estero e Córdoba. Alberto Tasso explica que Santiago del Estero pertence ao Chaco seco, e seus solos, clima e flora são fatores centrais para todas as atividades produtivas. O clima meridional, de invernos breves a longa estação seca permitem compreender a importância da água como determinante para povoação e para produção (TASSO; ZURITA, 2003-2004, p.112). Tasso e Carlos Zurita mostram ainda, sumariamente, que no território santiagueño há o que eles consideram algumas notas dominantes e que devemos expor aqui: primeiro que se trata de uma planície subtropical dilatada que ocupa 136.351 km² no norte da Argentina; segundo, possui duas estações definidas com um longo e intenso verão em que as temperaturas máximas normalmente superam os 40 graus, e um breve ainda acentuado inverno, com mínimas que vão às vezes até 10 graus abaixo de zero; terceiro que o padrão de semiaridez que impera no clima também se manifesta na escassez de chuvas, com a média anual de 600 mm, concentrada no verão; e por fim, que os solos são suscetíveis à erosão e em grande parte possuem sérios problemas de sódio e de salinidade (TASSO \& ZURITA, 2013, p.35). Nesse aspecto, observamos uma diferença importante com o semiárido brasileiro, que é a baixa temperatura no inverno.

A partir desse panorama geográfico, pretende-se entender como essas áreas semiáridas foram vistas e pensadas em meio às crises climáticas que as acometeram na década de 1930. No entanto, a seca será tratada como uma questão político-social e não somente geográfica. Porque ela pode revelar percepções do social que vão além da própria questão climática, e esse é o ponto que nos interessa particularmente. Por isso, para este trabalho, analisaremos, em específico, reportagens do jornal Correio da Manhã, do Rio de Janeiro, e do periódico El Mundo, de Buenos Aires. 
Ambos noticiaram as secas do Ceará e Santiago del Estero, respectivamente. Essas narrativas trouxeram à tona visões que estão para além do problema da seca em si. O Ceará e Santiago del Estero foram vistos, em diversos desses discursos, pela ótica do medo, do "outro" que necessitava ser tutelado pelo Estado, do encontro da capital com o interior.

Para tanto, nos valemos do método da História Comparada para esta reflexão. Segundo José D'Assunção Barros, por meio dele devemos perguntar: O que observar? Como observar? Por que comparar? E o que se espera com essa comparação? Dentro dessa perspectiva, o autor ressalta que devemos iluminar um objeto ou situação a partir de outro mais conhecido, fazer analogias, identificar semelhanças e diferenças entre essas duas realidades (BARROS, 2014, p.17). Barros explica, então, como Marc Bloch usou a História Comparada para realidades próximas, vizinhas, que tinham ambas um imaginário comum, repertórios de representações similares e um mesmo problema comum que as atravessava (BARROS, 2014, p.50). Nos remetemos, mais especificamente, ao modelo de História Comparada que Barros chama de História Comparada Problema. Ele compara este método com a imagem de dois triângulos articulados, mas cada um em seu próprio plano, onde apresentam um vértice comum que corresponde ao espaço temporal, e um segundo vértice comum que é o problema (BARROS, 2014, p.55) Temos o espaço temporal que é a década de 1930 e temos o problema comum que é imagem que esses dois países criaram naquele contexto sobre as regiões semiáridas. Neste aspecto, segundo sua metodologia, Barros apresenta possibilidades existentes na comparação entre o Brasil e a Argentina, assim como Marc Bloch fez com Inglaterra e França. Brasil e Argentina são próximos no espaço e no tempo e apresentam estruturas estatais análogas que acabam por assegurar o mínimo de similaridade. Contudo possuem diferenças inerentes às suas particularidades, pois apresentam marcas distintas e definidas nos seus processos históricos (BARROS, 2014, p.138).

Logo, de uma maneira geral, percebemos a possibilidade de uma história comparada entre esses países. No entanto, este trabalho prioriza 
uma perspectiva regional, localizada, que una as histórias do Brasil e da Argentina. Tal delimitação se deu pela necessidade de eleger uma escala de observação mais específica. Isso significa que "escolher a escala é definir os limites do trabalho comparativo" (BARROS, 2007, p.16). Em contrapartida, o desafio se dá, como explica Barros, em evitar as armadilhas do anacronismo, da generalização indevida, da indução mal encaminhada. O autor considera que comparar "é uma forma específica de propor e pensar as questões"(BARROS, 2007, p.4) por isso, a história comparada pode ser um método sofisticado na medida em que "será possível ainda a prática da 'iluminação recíproca'(...) que se dispõe a confrontar dois objetos ou realidades ainda não conhecidos de modo a que os traços fundamentais de um ponham em relevo os aspectos do outro" (BARROS, 2007, p.4).

É nessa perspectiva, portanto, que nos defrontamos com o tema das secas no Ceará e em Santiago del Estero, como possibilidade de análise tal como Barros aponta. Por meio das secas, encontramos os traços de similitude e os padrões de transformação no tempo na história nesses locais, respeitando as diferenças inerentes às suas trajetórias. Assim, nos interessa pensar como os discursos em torno das secas na década de 1930 no Brasil e na Argentina possibilitam comparar, no espaço-tempo, Ceará e Santiago del Estero.

Os semiáridos, na história do Brasil e da Argentina, ainda são relegados à pobreza e a um profundo desequilíbrio social, que tem um fundo histórico de longa duração. Por isso, pode-se revelar com essa comparação, discursos que perpassam a própria trajetória formativa de ambos países. Dentre esses discursos, destacamos para este trabalho o que Walter Mignolo considera como uma reprodução interna de um modelo moderno/colonial. Isso significa considerar que o "Occidente es una política imperial de la identidad" (MIGNOLO, 2017, p.137). Logo, devemos também, ao analisar os discursos que nos propomos neste trabalho, considerar o padrão colonial de poder; e que países, como Brasil e Argentina, estão inevitavelmente inseridos nele. Consideramos que essas 
noções fizeram parte da construção dos espaços semiáridos do Ceará e de Santiago del Estero, vistos pela ótica da modernidade não alcançada e sempre almejada, com uma população, por vezes, considerada incivilizada e inculta.

\section{POR UMA HISTÓRIA REGIONAL: OS SEMIÁRIDOS COMO POSSIBILIDADE DE ANÁLISE}

Antes de analisarmos os discursos dos periódicos, vale-nos pensar o que entendemos por história regional, e pelos conceitos de região, espaço e lugar que são essenciais para este trabalho. María Rosa Carbonari aponta a necessidade de uma reflexão que considere a relação da região tanto com o particular, como com o geral, em oposição a uma história que não inclua ou que minimize particularidades espaciais (CARBONARI, 2009, p.20-21). A autora explica que, em um dado momento, críticos das histórias nacionais haviam transformado as histórias regionais em meras histórias de um determinado lugar, com a pretensão de serem histórias nacionais (CARBONARI, 2009, p.22). Ou mesmo, uma vertente que passava a entender as regiões como recortes do espaço que interessava, pela funcionalidade econômica, ao mercado e/ou ao planejamento do desenvolvimento regional (CARBONARI, 2009, p.22). A região, ao fim e ao cabo, assumia a perspectiva de ser um mero exemplo da totalidade (CARBONARI, 2009, p.26). Além disso, ela passava a ser tida como um conceito relacional, sob o método hipotético-dedutivo. Ou seja, de acordo com Carbonari, se o global era projetado dentro da teoria da modernização econômica, as regiões que participavam desse processo de crescimento constante, tendiam à modernização (2009, p.27). A autora, assim, nos convida a pensar que as regiões não se explicam por tipologias, senão por processos que se gestam historicamente, e se vinculam à expansão do capitalismo que reordena os espaços. A região, como entidade concreta, se concebe como resultante de múltiplas determinações e se caracteriza por uma natureza transformada por heranças culturais, materiais, e por uma 
determinada estrutura social com suas próprias contradições. Para Carbonari, portanto, a região é um processo histórico geral em um quadro territorial menor, onde se combinam o geral e o particular (CARBONARI, 2009, p.28). Assim, cada região será entendida em sua totalidade através dos processos de base material que resultam da interação entre o homem e o meio (CARBONARI, 2009, p.28).

A análise de Carbonari, nos interessa em particular porque entendemos que as histórias do Ceará e de Santiago del Estero, relacionadas às secas e aos semiáridos, podem ser entendidas como um estudo das relações constituídas historicamente entre esses subespaços e os contextos maiores que as possibilitam e dão sentido (CARBONARI, 2009, p.28). Isso porque, o espaço regional, de acordo com a autora, não é fixo, ele é um espaço social com conjuntos heterogêneos que atuam sobre o presente e condicionam o futuro. Analisá-lo implica, portanto, vê-lo como um espaço dinâmico, em contínuo movimento (CARBONARI, 2009, p.28). Hélio Cardoso Jr. explica que a partir de uma história regional, "o historiador se torna andarilho ou pedestre [...] ele procura caminhar no solo como se percorresse por dentro o próprio objeto de trabalho" (CARDOSO JR., 2011, p.9). Para o autor, a partir dessa perspectiva, descobre-se "que o regional ou local é uma zona de intensidades históricas muito rica, na medida em que o pequeno foco leva a uma encruzilhada de linhas ou séries que permite entrever o todo" (CARDOSO JR., 2011, p.16).

Ao considerar a importância da história regional, entendemos por região o que Paulo César Gomes define como um conceito variado, que deve ser concebido a partir das multiplicidades da riqueza do objetivo investigado, assim como suas diferentes operacionalidades, recortes, e suas respectivas instrumentalidades (GOMES, 2000, p.49). Para este trabalho, compreende-se que "na afirmação de uma regionalidade há sempre uma proposição política, sob um ângulo territorial" (GOMES, 2000, p.72). Gomes entende que, se a região se gesta na questão política de fundo territorial, ela deve ser pensada colocando em jogo as comunidades 
de interesse identificadas a uma certa área e, finalmente, se propor uma discussão entre os limites da autonomia frente a um poder central (GOMES, 2000, p. 73). Por isso, é essencial entender o "fundamento político, de controle e de gestão de um território" (GOMES, 2000, p.73).

Ruy Moreira oferece um dado importante a esse respeito: com a segunda revolução industrial, na virada do século XIX para o XX, a intervenção sobre os espaços ocorreu em escala planetária "na forma de uniformização dos modos de vida e processamentos produtivos" (MOREIRA, 2007, p.56). Os espaços foram globalizados "em menos de um século, sob um só modo de produção, que unifica os mercados e valores, suprime a identidade cultural das antigas civilizações e traz com a uniformidade uma desarrumação socioambiental em escala inusitada" (MOREIRA, 2007, p.56). No entanto, nos anos 1950 e, principalmente, 1970, essa noção de uniformidade não era mais possível de ser pensada. Ruy Moreira explica, que era necessário reconhecer a relação em rede que surgia a partir da articulação entre diferentes lugares, e agia como uma nova forma de sociedade (MOREIRA, 2007, p.57). A partir dessas proposições, também se devia pensar o conceito de lugar. De acordo com Moreira, podemos entender "lugar como relação nodal e lugar como relação de pertencimento" (MOREIRA, 2007, p.61). Por isso, quando falamos de região e de lugar, neste trabalho, refletimos questões políticas e de relações de pertencimento. A partir desses conceitos, é válido destacar que entendemos espaço como o fio tenso entre a centralidade e alteridade, como explica Moreira. Essa tensão, para ele, é “o estatuto ontológico do espaço" (MOREIRA, 2007, p.64). O autor ainda ressalta que não importa o nome com que apareça - área, região, país ou continente - o espaço nasce da relação de ambientalidade, da relação de coabitação entre o homem e a diversidade da natureza, assim, "o homem materializa como ambiência, dado seu forte sentido de pertencimento"(MOREIRA, 2007, p.64).

Nesta perspectiva, entendemos a importância de uma história regional que estabeleça uma compreensão dos conceitos de região, lugar e espaço, porque tratamos de áreas em que o vínculo entre o ser humano 
e o meio ambiente é intrínseco, faz parte da formação dos semiáridos, e das disputas políticas que os cercam. As populações desses espaços (espaço como ambiência e sentimento de pertencimento), baseiam sua vida, economia, relações de trabalho, diretamente à terra onde habitam. Por isso, consideramos esses semiáridos como uma possibilidade de análise comparada, assim como uma história regional que identifique a importância do lugar.

\section{CORREIO DA MANHÃ E EL MUNDO: OS DISCURSOS SOBRE AS SECAS DO CEARÁ E DE SANTIAGO DEL ESTERO NA DÉCADA DE 1930}

Podemos refletir, a partir de uma história regional e da ideia de região vinculada ao pertencimento e às disputas políticas, como foram empregados certos discursos para o sertão do Ceará e para o semiárido santiagueño, na década de 1930. Cabe salientar, que neste contexto, o Brasil e a Argentina pensavam o papel do interior no todo nacional. Havia desde a década de 1920 uma crítica às influências estrangeiras nessas sociedades. Principalmente, no Brasil, o sertão era visto como o autenticamente nacional, porque não tinha influências externas. A população sertaneja passou a ser a representação do verdadeiro Brasil.

Já na Argentina havia também, nesse contexto, um olhar para dentro, para o que eles consideram a Argentina profunda (onde se encontra a região do Noroeste), e isso implicava pensar o ambiente rural e que tipo de país se queria nesse contexto.

Apesar das diferenças claras existentes, o Brasil tinha acabado de passar pela Revolução de 1930, com a entrada de Getúlio Vargas no poder e a ruptura com a classe oligarquia. Já a Argentina, pelo contrário, encontrava-se em meio à restauração agropecuária com a presidência de Agustín P. Justo. Em ambos os casos, se pensava na modernização do campo como um ponto importante para o desenvolvimento nacional. É nesse contexto que Aníbal Quijano afirma: no final do século XIX e durante o século XX, a América Latina questionava a noção de modernidade vinculada ao ideal europeu. No entanto, o fazia sustentando a ideia de que 
"a modernização não implica necessariamente a ocidentalização das sociedades e das culturas não-europeias" (QUIJANO, 2005, p.111). Nessa perspectiva, "um dos argumentos mais usados foi o de que a modernidade é um fenômeno de todas as culturas, não apenas da europeia ou ocidental" (QUIJANO, 2005, p.111). Contudo, como analisa o autor, pensar na América Latina e na modernidade é referir-se a três elementos que ele aponta como centrais: "a colonialidade do poder, o capitalismo, e o eurocentrismo" (QUIJANO, 2005, p.113). Isso significa que, historicamente, países como Brasil e Argentina, buscavam modelos de sociedade que não necessariamente se encaixavam nas suas realidades locais. Primeiro, olhou-se para a Europa, como o ideal de civilização e de progresso a serem alcançados, e depois ocorreu o mesmo em relação aos Estados Unidos. Tais escolhas podem ser consideradas a reprodução do mundo moderno/colonial, e é exatamente esse ponto de inflexão que nos interessa em particular para a compreensão dos discursos dos periódicos.

Cabe destacar que a escolha pelos jornais Correio da Manhã e El Mundo, não se dão em vão. Os dois meios de comunicação, além de retratarem a problemática da seca em suas regiões, possuíam grande tiragem nas capitais Rio de Janeiro e Buenos Aires, respectivamente. $O$ Correio da Manhã, com notas pequenas, ou reportagens que ocupavam uma página inteira sobre o problema da seca de 1932 e da própria história da população sertaneja, levou a um tipo de representação sobre o Ceará sertanejo na década de 1930. O periódico El Mundo não fez diferente. Após a seca de Santiago del Estero ter atingido o auge da fome e da miséria da população, em todo o mês de dezembro de 1937, ininterruptamente, fez uma verdadeira campanha assistencial em prol dos atingidos pela forte estiagem. Da mesma maneira, com notas pequenas, ou com reportagens que ocupavam páginas inteiras - destacando-se um número significativo delas - El Mundo retratou a campanha em prol dos atingidos pela seca santiagueña. Une-se a isso o fato de o periódico ter enviado a Santiago del 
Estero o escritor Roberto Arlt $^{2}$ que relatou a miserabilidade da seca de 1937 nas suas crônicas chamadas El infierno santiagueño.

Tânia de Luca explica as diversas possibilidades do uso de jornais como fonte histórica. Por meio deles, se pode refletir os inúmeros aspectos da vida social e política, principalmente, porque difundem valores e modos de vida de uma dada sociedade. Estudos têm destacado "as ambiguidades e hesitações que marcaram os órgãos da grande imprensa, suas ligações cotidianas com diferentes poderes (...) o peso dos interesses publicitários e dos poderes do momento" (LUCA, 2005, p.130). Para Maria Helena Capelato, "a análise do jornal como fonte e objeto pressupõe uma avaliação crítica desse documento, o que implica sua desconstrução" (CAPELATO, 2015, p.115). Por isso, "nesse processo, devem ser consideradas as circunstâncias históricas em que a análise foi produzida, os interesses em jogo e os artifícios utilizados pelos seus produtores" (CAPELATO, 2015, p.115).

Mikhail Bakhtin nos convida a pensar a importância da estética verbal do discurso. Isso porque, para o autor, quando escolhemos uma oração, a elegemos "em função do que queremos expressar com a ajuda dessa oração, selecionamos um tipo de oração em função do todo do enunciado completo que se apresenta à nossa imaginação verbal e determina nossa opção" (BAKHTIN, 1997, p.306).

Logo, certas falas só fazem sentido se estão conjugadas a determinados tipos de enunciados, como explica Bakhtin. Esses enunciados fazem parte de um certo contexto, que aspira algum objetivo e que deseja revelar alguma intencionalidade. Por isso, cabe-nos refletir, neste tópico, quais são as relações discursivas que colocaram, principalmente, na natureza semiárida, os males das desigualdades sociais existentes nessas áreas. Pensamos como a natureza, logo a seca, era vista dentro de certos binômios, como: litoral/interior, modernidade/atraso, que justificavam assim um suposto subdesenvolvimento vivido por essas regiões. Os periódicos, nesse sentido, tiveram um forte papel na

\footnotetext{
${ }^{2}$ Neste trabalho não trataremos das crônicas de Roberto Arlt em El Mundo, por serem tema mais específico. Para tal análise ver: ANDERMANN, Jens. El infierno santiagueño: sequía, paisaje y escritura en el Noroeste argentino. Iberoamericana, XII, 4, 2012, pp.23-43.
} 
disseminação desses discursos em relação a essas áreas e ao fenômeno das estiagens. Neste aspecto, entendemos que tais narrativas estão também inseridas na ideia de modernidade/colonialidade que fez parte da história da América Latina.

Sendo assim, fundado por Eduardo Bittencourt em 1901, o Correio da Manhã baseava-se em narrativas com forte teor de emoção, o que fazia com o que seus leitores pudessem participar dos fatos ocorridos (CADERNOS DE COMUNICAÇÃO, 2001, p.22). Além disso, o Correio deu espaço a novos desenhistas da época, por isso, suas reportagens continham fotos, ilustrações, charges e imagens (CADERNOS DE COMUNICAÇÃO, 2001, p.31); característica esta que o jornal aprimorou ao longo da sua trajetória. Por ser um jornal de grande tiragem no Rio de Janeiro, outras localidades menores passaram a reproduzir muitas das suas reportagens e artigos (CAMPOS, 2015, p.460). Segundo Ana Paula Freitas (2005), os principais articulistas do Correio da Manhã entre as décadas de 1920, 1930 e 1940, foram: Edmundo Bittencourt, o próprio proprietário do jornal; Mário Rodrigues que assumiu a direção do jornal em 1922; Leão Veloso Filho, cujo pseudônimo era Gil Vidal, que foi redator-chefe do jornal, e já havia tido uma carreira política em Alagoas; o senador alagoano Pedro da Costa Rego, redator-chefe em 1923 (houve algumas interrupções nessa função durante a sua trajetória) e Paulo Bittencourt, que recebeu do seu pai a direção do jornal em 1929, dentre outros colaboradores.

O Correio exercia, portanto, um forte prestígio e influência na opinião pública do país (FREITAS, 2005, p.73-74). De acordo com Raquel de Campos, mantinha sempre uma posição crítica e legalista (CAMPOS, 2013, p.1334), e foi considerado um periódico voltado para classe média urbana e seus pares.

A partir da trajetória do jornal, vejamos alguns exemplos de como o Correio pensou o sertão cearense. Nesta reportagem dizia-se:

Fortaleza, 19 (A.B) - Continua verdadeiramente angustiosa a situação em toda zona do sertão cearense. Nada pode dar uma ideia do que, na realidade, se vem passando no sertão brasileiro. Sexagenários, homens quase macróbios, experimentados na vida 
do sertão, afirmam que jamais o Ceará atravessou época tão dolorosa. A fome já bateu a todas as portas dos lares sertanejos, expulsando dali seus habitantes. E assim que eles emigram, dispondo-se a caminhadas intermináveis, pelas caatingas e pelas estradas ardentes que o sol inclemente transformou num brazeiro. Com a debandada começa a morrer gente pelos caminhos. Já não surpreende o quadro que se depara aos olhos do viajante: cadáveres de velhos e crianças estirados à margem das estradas. Tudo o que se possa imaginar de tenebroso está ainda aquém da calamidade que devasta o sertão cearense. Não será com paliativos que se pode amenizar o que aí está. A situação exige esforços excepcionais, compreensão mais calma do que tem a fazer (Correio da Manhã, 1932, p.2).

Neste trecho, a imagem apresentada ao leitor saltava aos olhos um quadro de pavor. Os "sexagenários, homens quase macróbios", a fome que batia em todas as portas dos lares, do migrante que caminhava interminavelmente pelas caatingas e pelas estradas ardentes, morrendo gente pelo caminho, os "cadáveres de velhos e crianças à margem das estradas"... ○ quadro era tenebroso e a situação exigia esforços excepcionais. Kênia Rios analisa: "[...] instaurado o pânico, a pauta principal passa a ser outra: o que fazer com os retirantes" (2014, p.69). Nessa trama, o pavor em relação às cenas dos retirantes era, portanto, um elemento discursivo importante para dar visibilidade a um tipo de olhar sobre o semiárido cearense. Parece-nos, nesse tipo de narrativa, que em razão da fome, as pessoas podiam passar a roubar comércios em busca de alimento, e o horror podia se instalar e se espalhar por toda a capital Fortaleza. Assim, aguçava-se um instinto de "barbárie" nessas populações.

Em trecho de artigo do dia 21 de setembro de 1930, o correspondente do Correio no Jaguaribe, narrava:

O Correio do Ceará noticia a chegada de uma família de retirantes, composta de 4 pessoas vindas de Passagem de Pedras, que narram cenas tristíssimas dos sertões do Jaguaribe, onde a fome impera. Dizem os informantes que o êxodo se acentua, estando as estradas que trazem a Fortaleza, cheias de famintos. O jornal pergunta onde estão as providencias do governo para socorrer os desgraçados sertanejos a braços com essa calamidade (Correio da Manhã, 1930, p.11).

Neste fragmento fica explícito como o êxodo dos sertanejos era tratado com um tom de pavor quando os mesmos "desgraçados 
sertanejos" iam para a capital Fortaleza "cheios de fome". Era necessário que esse quadro fosse resolvido pelo Estado. De acordo com Frederico de Castro Neves, "a presença da multidão exigindo proteção, vinha forçar essas autoridades a intervir, já que colocava em questão a 'segurança' social e ameaçava a ordem instituída" (NEVES, 2001, p.123).

Tratar os sertanejos como famintos, desgraçados em um sertão de tristeza onde a fome imperava, fez parte de um discurso fatalista em torno das cenas "tristíssimas" dos semiáridos. Ora, quando o Correio narrava esse quadro da seca, com famílias de retirantes "invadindo" as capitais "cheias de famintos", por mais que culpabilize o governo pelo estado de penúria em que viviam os sertões, relacionava às atitudes dos sertanejos diretamente a seca. Passamos a olhar com tristeza, penúria, desordem, os sertões da seca. Já se via como era comum a imagem de crianças barrigudas, famélicas e esqueléticas para retratar os sertões desde o século XIX. Isso se fixou no imaginário do semiárido e das retiradas das populações e suas famílias, homens, mulheres e crianças vistas como andrajosos a caminhar a esmo em um futuro que não previne as calamidades.

Victor Nunes Leal (2012) analisa que a figura do grande fazendeiro, do coronel, nas relações sociais do mundo rural nordestino e semiárido é de suma importância. O autor explica que em um dado momento da história o que se tornou mais comum foi a figura do fazendeiro que possuía propriedades e negócios, mas não necessariamente tinha dinheiro. O que se via pelo interior do país era o coronel sem grandes confortos de vida. Às vezes podia ter água encanada, luz elétrica e instalações sanitárias, o que fazia com que a população que vivia da roça sempre visse essa figura do grande latifundiário como um homem rico, ainda que não o fosse; rico em comparação a sua pobreza. Nesse aspecto, era também esse proprietário de terra ou gado que conseguia os financiamentos bancários devido ao seu prestígio político. Então, era para ele que o sertanejo apelava "nos momentos de apertura, comprando fiado em seu armazém para pagar com a colheita, ou pedindo dinheiro, nas mesmas condições, para outras necessidades" (LEAL, 2012, p.24). 
Foi essa figura da oligarquia algodoeira-pecuária que dominou o discurso da seca, a partir do momento em que percebeu que através dele ela podia se beneficiar com o envio de verbas para o seu combate. Em 1932, especificamente, estamos falando da relação dessa oligarquia com o envio de recursos pela Inspetoria Federal de Obras Contra as Secas (IFOCS) Havia um discurso de uma elite local que, de acordo com Rafael Ribeiro, ressaltava: "a necessidade de dar à região uma 'compensação' por seus azares climáticos de um auto-desenvolvimento em função da natureza hostil é o pano de fundo dessa tragédia" (RIBEIRO, 1999, p.75). Nesse sentido, quando o Correio da Manhã narrava a seca culpabilizando, por vezes, a natureza e sua população pelas mazelas existentes, acabava por não problematizar essas relações de dependência que configuram os sertões, e que estão na base das desigualdades sociais existentes.

Por isso, a seca revela a importância da região enquanto conceito, enquanto pertencimento e correlação de forças, porque as relações sociais intrínsecas ao latifúndio fazem parte da dinâmica desses espaços.

Sendo assim, devemos compreender as estratégias discursivas do Correio como produtoras de objetos, normas e modelos. Kênia Rios ressalta, portanto, que "no momento em que a seca é declarada, a cidade começa a tecer uma rede de relações com as quais se cria um cenário de terror. Anúncios alarmantes pedem socorros, e comerciantes amedrontados exigem medidas do governo" (RIOS, 2014,p.67).

No que se refere ao periódico El Mundo, vejamos os pontos de similitude com o Correio da Manhã e com o discurso, principalmente, do medo das multidões advindas da seca. O jornal foi criado em 1928 por Alberto Haynes, e tinha um tamanho menor do que era comum à época, por isso, foi considerado o primeiro diário tabloide da Argentina. Tornou-se um periódico de baixo custo, e que priorizava histórias populares. El Mundo dava espaço para contos, comentários, modas, trabalhos e concursos semanais de diversas categorias, como o futebol. A partir disso, neste contexto, El Mundo passou a existir junto com La Nación (1870) e La Prensa (1870) (CATTAZZURA, 2009, p.83-84). Para Beatriz Sarlo, o periódico 
proporcionava um material com artigos breves, que podiam ser lidos por inteiro em uma viagem ao trabalho. Era um novo tipo de periodismo já existente com a criação do vespertino Crítica, fundado em 1913. No periódico Crítica havia ritmo, rapidez, seções esportivas, de cinema, sobre a mulher, a vida cotidiana, configurando esse novo tipo de periódico para os setores médios e populares (SARLO, 2003,p.20).

Nesse sentido, considerando a trajetória de El Mundo, vejamos uma reportagem de um correspondente que dizia:

\begin{abstract}
Otro despacho publicado también por "El Liberal", al referirse a la forma en que la localidad de Herrera, en Avellaneda, sufre los rigores de la sequía, expresa: "Se han registrado muchos casos de defunción, principalmente entre los niños, por agotamiento físico, como en el caso del menor M. Verón, de 17 años, que, como consecuencia de su debilitamiento, contrajo una grave dolencia que lo llevó a la tumba. Además, grupos numerosos de pobladores imploran la caridad pública en los almacenes y casas particulares, siendo más numerosas en los trenes y provocando escenas patéticas como jamás se ha visto en este pueblo." (El Mundo, 1937, p.5)
\end{abstract}

Nesse trecho percebemos como a seca expressava a morte e o caos. A morte de um menino de 17 anos pelo esgotamento físico, o caos com os grupos numerosos de pessoas que imploravam a caridade pública, provocando cenas nunca antes vistas naquele povoado. Tal cena parece-nos sucumbir à total ausência de ordem, de civilidade e, sobretudo, de pavor com a morte da criança e a população que esmolava pelas ruas e trens. O extremo abandono em que vivia a população santiagueña estava posto e o pânico estava instaurado aos leitores da capital de Buenos Aires. E era preciso - bem como vimos no caso brasileiro - refletir o que fazer com essa população. Quando El mundo dizia que essas cenas eram patéticas, reforçava também um olhar de estranhamento em relação à população de Santiago del Estero.

Por isso, ressaltamos o que Bakhtin explica: não devemos lidar com a palavra de forma isolada, ela deve ser entendida por meio de um enunciado em seu "sentido concreto" (BAKHTIN, 1997, p.311-312). Isso significa, que devemos compreender não somente a significação da palavra "enquanto palavra da língua"(BAKHTIN, 1997, p.311-312), mas que 
há que adotar a partir dela "uma atitude responsiva ativa (simpatia, concordância, discordância, estímulo à ação)" (BAKHTIN, 1997, p.311-312). Ou seja, "ao escolher a palavra, partimos das intenções que presidem ao todo do nosso enunciado, e esse todo intencional, construído por nós, é sempre expressivo" (BAKHTIN, 1997, p.311-312). Entendemos, portanto, que quando os periódicos dispõem de certas palavras, elas devem ser entendidas não de maneira isolada dentro de uma formulação qualquer, sem intenção de sê-lo, mas sim com a sua expressividade, que se relaciona diretamente ao que se deseja mostrar aos seus leitores, principalmente, em meio às secas. Bakhtin destaca que "escolhemos a palavra de acordo com a sua significação que, por si só, não é expressiva e pode ou não corresponder ao nosso objetivo expressivo em relação com as outras palavras, isto é, em relação com o todo de nosso enunciado" (BAKHTIN, 1997, p.312). Para o autor é importante considerar o contato existente entre a significação linguística e a realidade concreta, que se dá no enunciado, e esse ponto de contato que leva à expressividade, às emoções, ao juízo de valor.

Em outra reportagem observamos esse mesmo discurso de uma "total desordem" na região devido à seca:

Santiago del Estero, 26 (de nuestro corresponsal) - La llegada a esta ciudad de numerosas familias enteras venidas a pie de diversos puntos del departamento Capital, donde la mortandad de las haciendas y de los últimos animales domésticos, así como la pérdida total de cosechas y el agotamiento de los últimos pozos de agua potable asume características impresionantes, está creando una situación delicada dentro de la capital misma. En las afueras de Santiago es dable ver campamentos improvisados compuestos de hombres, mujeres y niños que pernoctan a orillas de los caminos e imploran caridad a los viajeros que entran y salen de ciudad. Esto hace deducir que, en algunos puntos, donde la vida se ha hecho insostenible, se ha iniciado el éxodo de pobladores (El Mundo, 1937, p.5).

Homens, mulheres e crianças imploravam a caridade, a situação se tornava insustentável, numerosas famílias chegavam à capital de Santiago del Estero a pé e ficavam pelo caminho. A morte dos animais, a perda das colheitas e a falta de água compunham esse cenário de horror. Era preciso que o governo tomasse alguma posição em relação à população sedenta. 
O olhar de estranhamento de um correspondente que vinha da capital se fazia notório. A situação da seca era narrada como um quadro que beirava a incivilidade, a falta de organização e de ordem.

Havia acampamentos improvisados pela cidade, e pessoas que imploravam a caridade pelos caminhos. A vida estava insuportável. Se iniciava, assim, o êxodo das populações. O drama dos santiagueños chegava a Buenos Aires, a pobreza naturalizada era confirmada com a campanha filantrópica que foi feita para a região. Víveres, roupas e dinheiro eram enviados para Santiago del Estero por meio desta campanha. A listagem com o nome dos colaboradores era posta no periódico El Mundo, resaltando que Buenos Aires tratava com caridade esses homens, mulheres e crianças que sofriam as angústias da seca. A capital, então, fazia sua parte para minorar essa tragédia.

Alberto Tasso explica que a estrutura santiagueña deve ser entendida dentro das relações de convivência entre os grandes proprietários e os campesinos sem terras, com um regime de dominação social de acentuada rigidez. Nessa configuração estabeleceram-se, durante três séculos, as chamadas estâncias e as zonas campesinas, que eram resíduos das antigas "encomiendas" e "pueblos de indios".

Assim viviam brancos donos de terra de um lado e, do outro, camponeses e assalariados índios e mestiços. É nesse contexto que surge a agricultura de irrigação e com ela novos padrões de distribuição de terra, novos sistemas produtivos e consequentemente novos tipos sociais (TASSO, 2000, p. 147). Aparecem, então, em Santiago "las fincas grandes organizadas con concepto empresarial, los colonos inmigrantes y sus pequeñas chacras y los campesinos como fuerza de trabajo, residente en los intersticios o aún dentro de la gran propiedad bajo la antigua institución del 'agregado'”(TASSO, 2000, p. 147).

Por isso, é necessário pensar estas configurações sociais quando analisamos o discurso da seca. Porque elas revelam um sistema social em que existia, de fato, um alto grau de dominação dos grandes proprietários sobre os pequenos, com alianças e mecanismos de legitimação de 
dependência. Essas relações silenciavam as tensões sociais existentes entre diversos interesses que configuravam a região santiagueña, como analisa Tasso. A seca, neste aspecto, deve ser pensada e entendida dentro dessa conjuntura em que viviam os santiagueños. Logo, quando El Mundo narrava a estiagem com um tom fatalista, culpabilizando, por vezes, a natureza pela desigualdade existente, assim como o Correio, acabava por não problematizar essas diversas correlações de poder que permeavam este território. Novamente, entendemos as disputas dentro desse espaço, como um campo de força que faz o próprio espaço. Por isso, reiteramos a importância de uma história regional e mais localizada, que abre campos de possibilidade para o entendimento de projetos de poder.

Por fim, Bronislaw Geremek também pode nos ajudar neste ponto. De acordo com o autor, "numa atmosfera de grande expectativa, em que - clima tenso parecia anunciar uma catástrofe para o sistema social vigente, as classes baixas surgiam como algo ainda mais ameaçador" (GEREMEK, 1995, p.9). Geremek está se referindo, principalmente, a como os pobres eram retratados na literatura europeia. Pensamos se o caso analisado por ele também não pode elucidar o medo que se tinha de que os cearenses e santiagueños tomassem as rédeas dessa situação e se rebelassem.

Aqui, transportamos essas visões, sobre as classes baixas, para os casos do Brasil e da Argentina. Ou seja, também é possível refletir como o pobre foi retratado nesses países dentro do campo que Geremek chama de código de normas e éticas. Isso significa que a "inviolabilidade da propriedade, a proteção das instituições e da ordem pública, a defesa de um determinado sistema de relações [...]"(GEREMEK, 1995, p.9) fizeram com que houvesse atitudes de "desconfiança e suspeita"(GEREMEK, 1995, p.9) sobre esse indivíduo pobre. Daí reiteramos que as diversas falas do Correio da Manhã e de El Mundo se assemelhavam com esse tipo de visão sobre populações pobres, pensadas por Geremek nos períodos das Idades Média e Moderna europeias. O autor ainda ressalta que "no plano societário o pobre era tratado como alguém que subvertia a ordem social 
e era socialmente perigoso" (GEREMEK, 1995, p.10). Sendo assim, quando os periódicos falavam das secas e pediam soluções para as mesmas, muitas destas soluções atreladas ao controle do pobre, ao medo do desemprego, das migrações, das revoltas, eles os viam como essa classe socialmente perigosa. Consideramos que essa noção faz parte da história das populações pobres no Ocidente, e que pode ser válida para pensar uma história mais local como as do Ceará e de Santiago del Estero. Novamente, a região como campo de disputa política e como relação de pertencimento é fundamental para compreensão dessas narrativas.

Sumariamente, podemos entender como esses discursos, do Correio da Manhã e de El Mundo, afirmavam o olhar que as capitais tinham sobre o interior. Um semiárido triste, uma população faminta, uma vida de desesperança; é a seca que tornava-se o tema central nos discursos, logo, era a natureza detentora do caos e das mazelas dessas regiões. As cenas narradas pelos jornais aumentavam o pavor da população das cidades em relação aos imigrantes do campo, advindos da seca, que, por conta da fome roubavam, saqueavam, transmitiam doenças. Tanto o Brasil, quanto a Argentina, no contexto da década de 1930, se utilizaram de medidas de controle para conter essa população que "invadia" as capitais, com ajuda de autoridades locais. Na Argentina, especificamente, foram tomadas medidas de racionalização da imigração, ações institucionais capazes de garantir a contenção necessária para os desprotegidos e desempregados, educação agrícola para jovens e mulheres, promoção da colonização e organização do trabalho para combater o desemprego e seus "delírios" (vagabundagem e mendicância) (GIRBAL-BLACHA, 2003, p.385).

Voltamos, por fim, à ideia de modernidade/colonialidade para pensar o discurso do medo, enfoque que destacamos nas narrativas desses jornais. Podemos nos valer desta noção para entender que o medo dessas multidões, o medo do flagelo, da seca, das migrações, estava relacionado diretamente a uma ideia de sociedade, que via essas áreas pelo espectro do atraso, e sua população como o outro, que devia ser tutelado e civilizado em nome da modernidade e do progresso. Ora, se a natureza era um 
problema que fazia com que as populações dos semiáridos vivessem sob o jugo de uma vida subdesenvolvida, se somente a modernidade podia ser a maneira pela qual os semiáridos sairiam dessa condição, e se entendemos o espaço como campo de disputa política, as narrativas dos jornais acabam por reforçar, então, antigas noções sobre essas áreas que desconsideravam as formas de vida locais. É sabido que a seca é um momento em que, de fato, situações extremas ocorrem, mas devemos problematizar e desnaturalizar visões que apresentam os semiáridos por meio das linhas de progresso e de modernidade, como se somente elas fossem maneiras possíveis de desenvolvimento social. Mignolo analisa, por fim, refletindo esta normativa da modernidade:

(...) o imaginário do mundo moderno/colonial surgiu da complexa articulação de forças, de vozes escutadas ou apagadas, de memórias compactas ou fraturadas, de histórias contadas de um só lado, que suprimiram outras memórias, e de histórias que se contaram e se contam levando-se em conta a duplicidade de consciência que a consciência colonial gera (MIGNOLO, 2005, p.37-38).

Acreditamos, portanto, que isso ocorreu claramente na história local de países como o Brasil e a Argentina. Esse mundo moderno/colonial deixou seus rastros na forma de se entender os sertões cearenses e o bosque santiagueño. Também tentou apagar memórias, fraturar histórias, suprimir formas de ver, pensar e agir dessas populações, em nome do mundo moderno/colonial.

\section{CONSIDERAÇÕES FINAIS}

Quando pensamos no mundo moderno/colonial como possibilidade de análise, ou mesmo como fio condutor deste trabalho, abrimos como campo de reflexão o que Mignolo chama de uma epistemologia fronteiriça, em contrapartida a um discurso que defenda uma unidade do idioma, da pureza de sangue e da razão. Assim, nasce a necessidade de um novo paradigma a partir da emergência do local. Por isso, consideramos a história regional, se aproximando para uma história do lugar, fundamental 
para esta análise comparada entre Brasil e Argentina. A partir das narrativas dos periódicos Correio da Manhã e El Mundo, pode-se perceber como esses países consideravam intervir nos semiáridos cearenses e santiagueños em períodos de seca.

Quando os jornais reproduziam discursos que viam na natureza semiárida, no clima, e na sua população, as mazelas existentes para a situação em que se encontravam, não deixavam de perpetuar uma narrativa que considerava essas áreas como atrasadas, por vezes, avessas à modernidade. Reforçava-se, com esse tipo de visão, uma antiga ideia de que era necessário civilizar esses espaços, e reproduzia-se, assim, o mundo moderno/colonial. Destacamos que essa reprodução foi realizada com novos contornos e novas roupagens, mas que ainda via na modernidade o único caminho possível para o desenvolvimento dessas regiões. Civilizar significava, neste sentido, intervir nessas lugares em nome da modernidade e do progresso. Também sabemos que uma seca, em seu estado de crise climática, ocasiona uma onda de morte, migrações, fome, sede e desemprego.

Contudo, pensamos essas consequências como causas diretas das conjunturas sociais, que independem da seca. Essas regiões, historicamente, nunca estão preparadas para uma forte estiagem, e suas desigualdades sociais não dependem do fenômeno em si.

Logo, quando o interior do Ceará e de Santiago del Estero, foram vistos pela ótica da natureza-problema, eles passavam a ser pensados como o outro, o diferente, sobretudo, em relação à população do litoral. Por isso, as narrativas dos jornais eram permeadas de um tom de pavor, de medo, e da necessidade de que se controlassem essas populações em meio às secas. Pelo mesmo motivo, é preciso ir além da própria narrativa em si, porque ela pode encarnar uma visão já preestabelecida, dotada, muitas vezes, de estigmatizações sobre essas áreas. Avançar rumo ao interior, ainda mais um interior acometido pela seca, era se deparar com uma realidade diferente das capitais. Não é estranho supor, que em meio a uma crise climática, o discurso para que se interviesse nesses locais de 
modo a tirá-los daquela situação de penúria, fosse vinculado às ideias de modernidade e progresso. Tratava-se de uma conjuntura em que era comum, para esses países, afirmar que a ausência desses fatores fazia com que as populações não conseguissem encarar uma seca. Por isso, consideramos os periódicos como construtores de representações, por vezes, forjadas do mundo dos semiáridos cearenses e santiagueños. Entendemos que seus discursos estiveram intimamente relacionados com ideias de poder e de dominação em voga na década de 1930. A partir dessas narrativas se consolidaram visões que se perpetuam até os dias atuais, muitas das quais, ainda olham para os semiáridos pela ótica da pobreza, das migrações, da penúria e do sofrimento.

\section{FONTES}

Aspectos dantescos do flagelo. Correio da Manhã. Rio de Janeiro, Ano XXXI, $\mathrm{n}^{\circ} 11458,20$ de abril de 1932.

A dolorosa retirada das infelizes famílias sertanejas para a capital do Estado. Correio da Manhã. Rio de Janeiro, Ano XXX, n¹0.966, 21 de setembro de 1930.

Niños muertos por falta de agua. El Mundo, Buenos Aires: Año X, 20 de diciembre 1937.

Huyendo del desastre empiezan a llegar a Santiago numerosos pobladores de toda la Campaña. El Mundo. Buenos Aires: Año X, 27 de diciembre de 1937.

\section{REFERÊNCIAS}

AB'SÁBER, Aziz Nacib. Sertões e sertanejos: uma geografia humana sofrida. Dossiê Nordeste Seco. Revista Estudos Avançados 13 (36), São Paulo, pp.7-59, $1999 . \quad$ Disponível em: https://doi.org/10.1590/S0103-40141999000200002. Acesso em 29 de maio 2020.

ANDERMANN, Jens. El infierno santiagueño: sequía, paisaje y escritura en el Noroeste argentino. Iberoamericana, XII, 45, (2012), pp.23-43. Disponível em: https://doi.org/10.5167/uzh-71180. Acesso em 28 de maio 2020.

ANDRADE, Manuel Correia de. O Nordeste e a questão regional. São Paulo: Editora Ática S.A, 1988. 
ANDRADE, Manuel Correia de. Paisagens e problemas do Brasil. (Aspectos da vida rural brasileira frente a industrialização e ao crescimento econômico). $5^{\text {a }}$ Ed. São Paulo: Editora Brasiliense, 1977.

BAKHTIN, Mikhail. Estética da criação verbal. [tradução feita a partir do francês por Maria Emsantina Galvão G. Pereira revisão da tradução Marina Appenzellerl.]. 2a ed. São Paulo: Martins Fontes, 1997 (Coleção Ensino Superior).

BARROS, José D’Assunção. História Comparada. Petrópolis: Ed. Vozes, 2014.

BARROS, José D'Assunção. História Comparada - um novo modo de ver e fazer a História - Revista de História Comparada, volume 1, número 1, jun./2007, pp.1-30. Disponível em: http://www.ppghc.historia.ufrj.br/index.php/destaque/publicacoes/revista-d e-historiacomparada. Acesso em 12 de maio 2020

BOBBA, María Elvira. Causas de las sequias de la región del NOA (Argentina). Revista Geográfica de América Central. Número Especial EGAL, 2011- Costa Rica II Semestre 2011, p.1-19. Disponível em: https://www.revistas.una.ac.cr/index.php/geografica/article/view/2498.

Acesso em 23 de maio 2020

CADERNOS DE COMUNICAÇÃO, Série Memória. Correio da Manhã compromisso com a verdade. Rio de Janeiro: Prefeitura da cidade do Rio. Secretaria Especial de Comunicação Social, 2001. Disponível em: http://wwwO.rio.rj.gov.br/arquivo/publicacoes-cadernos-sub-memoria.html. Acesso em 25 de maio 2020

CAMPOS, Raquel Discini de. A educação do corpo feminino no Correio da Manhã (1901-1974): magreza, bom gosto e envelhecimento. Cadernos Pagu (45), julho-dezembro de 2015, pp.457-478. Disponível em: http://dx.doi.org/10.1590/18094449201500450457. Acesso em 16 de maio 2020

CAMPOS, Raquel Discini de. Floriano de Lemos no Correio da Manhã, 1906-1965. História, Ciências, Saúde - Manguinhos, Rio de Janeiro, v.20, nov. 2013, p.1333-1352. Disponível em: https://doi.org/10.1590/S0104-59702013000400013. Acesso em 15 de maio 2020

CARBONARI, María Rosa. De cómo explicar la región sin perderse en el intento. Repasando y repensando la Historia Regional. História Unisinos 13(1):19-34, Janeiro/Abril 2009. Disponível em: doi: 10.4013/htu.2009.131.02

CAPELATO, Maria Helena Rolim. "A imprensa como fonte e objeto de estudo para o historiador." In: VILLAÇA, Mariana; PRADO, Maria Ligia Coelho 
(Org.). História das Américas: fontes e abordagens historiográficas. led.São Paulo: Humanitas, 2015, v. 1, p. 114-136.

CARDOSO JR, H. R. O CONCEITO DE REGIÃO E PROBLEMAS FILOSÓFICOS: Significado epistemológico da história regional e a constituição histórica do "espaço liso" e do "espaço estriado". Revista Tempo, Espaço e Linguagem (TEL), $\quad$ v. 2 n $n^{\circ} 3 \quad$ p.07-21 Set./Dez. 2011. Disponível: https://www.revistas2.uepg.br/index.php/tel/issue/view/270. Acesso em 05 de maio 2020

CASTRO, Josué de. Geografia da fome (Dilema brasileiro: pão ou aço). $10^{a}$ Ed. Rio de Janeiro: Revista Antares, 1984.

CATTARUZZA, Alejandro. Historia de la Argentina (1916-1955). $1^{a}$ ed. Buenos Aires: Siglo Veintiuno Editores, 2009.

DUQUE, Guimarães. O Nordeste e as lavouras xerófilas. Fortaleza: Banco do Nordeste do Brasil. 2004.

FREITAS, Ana Paula Saraiva. A presença feminina no cangaço: práticas e representações (1930-1940). Dissertação (Mestrado). Universidade Estadual Paulista Júlio de Mesquita Filho. Faculdade de Ciências e Letras de Assis, 2005. Disponível em: http://hdl.handle.net/11449/93408. Acesso em 02 de jun. 2020

GEREMEK, Bronislaw. Os filhos de Caim. Vagabundos e miseráveis na literatura europeia 1400-1700. Tradução do polonês Henryk Siewierski São Paulo: Companhia das Letras, 1995.

GIRBAL-BLACHA, Noemí María. Riqueza, poder y control social. Acerca de las estrategias empresariales agrarias en la Argentina (1900-1950). Anuario IEHS. No 18, Tandil, UNCPBA, 2003, pp.367-395

GOMES, Paulo César da Costa. "O conceito de região e sua discussão." In: CASTRO, Iná Elias de; GOMES, Paulo César da Costa; CORRÊA, Roberto Lobato(Org.),Geografia: conceitos e temas. $2^{\text {a }}$ ed - Rio de Janeiro: Bertrand Brasil,2000, pp.49-76.

LEAL, Victor Nunes. Coronelismo, Enxada e Voto. O município e o regime representativo no Brasil. $7^{\text {a }}$ edição. São Paulo: Companhia das Letras, 2012.

LUCA, Tânia Regina de. "Fontes impressas: história dos, nos e por meio dos periódicos". In: MOREIRA, Ruy. Da região à rede e ao lugar: a nova realidade e o novo olhar geográfico sobre o mundo. Revista etc...., espaço, tempo e crítica. $\mathrm{N}^{\circ} 1$ (3), VOL. $1,1^{\circ}$ de junho de 2007, pp.55-70. Disponível em: http: //www.uff.br/etc. Acesso em 05 de jun. 2020

MIGNOLO, Walter D. "Educación y decolonianidad: aprender a desaprender para poder re-aprender." En: GIULIANO, Facundo. Rebeliones éticas, 
palabras comunes. Conversaciones (Filosóficas, Políticas, Educativas). Buenos Aires: Colección Educación: Otros Lenguajes. Miño y Dávila. Editores, 2017.

MIGNOLO, Walter D. A colonialidade de cabo a rabo: o hemisfério ocidental no horizonte conceitual da modernidade. In: LANDER, Edgardo (org.). A colonialidade do saber: eurocentrismo e ciências sociais. Perspectivas latino-americanas. Colección Sur Sur, CLACSO, Ciudad Autónoma de Buenos Aires, Argentina, setembro 2005, pp. 33-49. Disponível

em: http://biblioteca.clacso.edu.ar/ar/libros/lander/pt/lander.html. Acesso em 03 de jun. 2020

NEVES, Frederico de Castro. Getúlio e a seca: políticas emergenciais na era Vargas. Revista Brasileira de História. v. 21, n40, SP, 2001, pp. 107-131. Disponível em: http://dx.doi.org/10.1590/s0102-01882001000100006. Acesso em 05 de jun. 2020

QUIJANO, Aníbal. Colonialidade do poder, eurocentrismo e América Latina. In: LANDER, Edgardo (org.). A colonialidade do saber: eurocentrismo e ciências sociais. Perspectivas latino-americanas. Colección Sur Sur, CLACSO, Ciudad Autónoma de Buenos Aires, Argentina, setembro 2005. pp.107-130.

Disponível

em: http://biblioteca.clacso.edu.ar/ar/libros/lander/pt/lander.html. Acesso em 10 de jun. 2020

RIBEIRO, Rafael Winter. Seca e Determinismo: a Gênese do Discurso do Semiárido Nordestino. Anuário do Instituto de Geociências - UFRJ, Volume 22 / 1999, pp. 60-91. Disponível em: http://www.ppegeo.igc.usp.br/index.php/anigeo/issue/view/239. Acesso em 20 de jun. 2020

RIOS, Kênia de Sousa. Isolamento e poder: Fortaleza e os campos de concentração na seca de 1932. Fortaleza: Imprensa Universitária, 2014.

SARLO, Beatriz. Modernidad periférica: Buenos Aires 1920-1930. $7^{\mathrm{a}}$ ed. $3^{\mathrm{a}}$ reimp. Buenos Aires: Nueva Visión, 2003.

TASSO, Alberto \& ZURITA, Carlos. Aves de paso. Los trabajadores estacionales de Santiago del Estero. Trabajo y Sociedad, $n^{\circ} 21$, Invierno 2013, Santiago del Estero, Argentina, pp.33-47. Disponível em: https://www.redalyc.org/articulo.oa?id=387334693004. Acesso em 22 de jun. 2020

TASSO, Alberto. La protesta de agua. Una movilización de agricultores santiagueños en 1926. Sociohistórica, 2000, Nro. 7, pp. 145-180. Disponível em: http://www.sociohistorica.fahce.unlp.edu.ar/. Acesso em 25 de jun. 2020. 
TASSO, Alberto \& ZURITA, Carlos. Un caso de expansión agraria seguido por depresión. Santiago del Estero, 1870-1940. POBLACIÓN Y SOCIEDAD N ${ }^{\circ}$ 10/11, 2003-2004, pp.109-136.

Disponível em: https://dialnet.unirioja.es/ejemplar/248320 